Revista Brasileira de Agricultura Irrigada v.10, nº.4, p. 787 - 798, 2016

ISSN 1982-7679 (On-line)

Fortaleza, CE, INOVAGRI - http://www.inovagri.org.br

DOI: $10.7127 /$ rbai.v10n400436

Protocolo 436.16 - 10/07/2016 Aprovado em 14/08/2016

\title{
USO DE CARBONATO, ÓXIDO E SULFATO DE CÁLCIO EM ALTA CONCENTRAÇÃO EM TUBOS GOTEJADORES
}

Fábio Jordão Rocha ${ }^{1}$, Rubens Duarte Coelho ${ }^{2}$, Marconi Batista Teixeira ${ }^{3}$, Frederico Antonio Loureiro Soares ${ }^{3}$, Jorge Luis Copquer dos Santos Júnior ${ }^{4}$, Fernando Nobre Cunha ${ }^{5}$, Nelmício Furtado da Silva ${ }^{5}$

\begin{abstract}
RESUMO
Partindo da hipótese de que o uso de carbonato de cálcio, óxido de cálcio e sulfato de cálcio em alta concentração em tubos gotejadores via água de irrigação causam obstrução de tubos gotejadores, objetivou-se com este estudo avaliar a obstrução de emissores por precipitados químicos de carbonato de cálcio, óxido de cálcio e sulfato de cálcio em alta concentração. As doses utilizadas foram 10 vezes a solubilidade de cada produto (660 mg L-1, $13 \mathrm{~g} \mathrm{~L}^{-1}$ e 24,5 g $\mathrm{L}^{-1}$, respectivamente). Para o ensaio foram utilizados quatro modelos de tubos gotejadores autocompensantes, com os gotejadores dispostos em dois sentidos (orifício do gotejador voltado para cima e para baixo). Os mesmos foram inseridos em quatro níveis diferentes em uma Bancada com estrutura metálica instalada no Laboratório de Irrigação do DERESALQ/USP. Adotou-se como um ciclo do ensaio, duas aplicações e uma leitura de vazão, repetindo-se duas vezes o ciclo e, posteriormente determinava-se a vazão média $\left(\mathrm{q}_{\mathrm{m}}\right)$, coeficiente de variação de vazão (CV) e uniformidade de distribuição de água (UD). O modelo M4 foi o que apresentou a maior redução para a medição de vazão média. A aplicação de cal virgem diretamente na linha lateral foi o que ocasionou os maiores distúrbios de vazão para os diferentes modelos de gotejadores ensaiados.
\end{abstract}

Palavras-chave: Entupimento, irrigação localizada, precipitados químicos.

\section{USE OF CARBONATE, OXIDE AND CALCIUM SULFATE IN A HIGH CONCENTRATION IN DRIPLINE}

\footnotetext{
ABSTRACT

${ }^{1}$ Eng. Agrônomo, Doutorando, Departamento de Engenharia Rural, Escola Superior de Agricultura Luiz de Queiroz, Universidade de São Paulo, Piracicaba, SP, C.P.: 9, CEP: 13418-900, fone (0xx19) 3447-8551, email: fjrocha@esalq.usp.br

${ }^{2}$ Eng. Agrônomo, Prof. Livre Docente, DER - ESALQ/USP, Piracicaba, SP, email: rdcoelho@usp.br

${ }^{3}$ Eng. Agrônomo, Prof. Dr. Instituto Federal Goiano - IFGoiano - Rio Verde, GO, email: marconibt@gmail.com

${ }^{4}$ Eng. Agrônomo, Doutor, DER - ESALQ/USP, Piracicaba, SP.

${ }^{5}$ Eng. Agrônomo, Doutorando em Ciências Agrárias - Agronomia, IFGoiano - Câmpus Rio Verde, Rio Verde, GO.
} 
Assuming that the different forms of calcium that can be found in irrigation water or used through irrigation water fertilizers cause obstruction of drippers, aimed this study was to evaluate the obstruction of emitters by chemical precipitated calcium carbonate calcium oxide and calcium sulfate in a high concentration. The doses used were ten times a solubility of each product (66 $\mathrm{mg} \mathrm{L}^{-1}, 1,3 \mathrm{~g} \mathrm{~L}^{-1}$ and 2,45g $\mathrm{L}^{-1}$ ) in respect. For the test were used four models of self-compensating drippers arranged in two directions (up and down) and placed in a metal bench at four different levels. Adopted as the test cycle, two applications and one reading of flow, twice repeating the cycle and, later determined the average flow, coefficient of variation of emitter flow and uniformity of distribution. The model M4 was the one to show the biggest reduction for the average flow measurement. The application of lime directly on the sideline was what caused the higher flow disturbances to the different models tested drippers.

Keywords: Clogging, drip irrigation, chemical precipitates.

\section{INTRODUÇÃO}

O entupimento de emissores continua sendo o principal problema em sistemas de irrigação por gotejamento. Embora informações quanto aos fatores que causam o entupimento estejam disponíveis, o controle por medidas preventivas nem sempre tem êxito, elevando os custos de manutenção e recuperação do sistema (TEIXEIRA et al., 2005; COELHO, 2007).

Diversos fatores podem provocar o entupimento parcial ou a completa obstrução dos orifícios de tubos gotejadores, prejudicando o fluxo de água e a sua distribuição ao longo das laterais, reduzindo, conseqüentemente a eficiência do sistema. Dentre tais fatores, destacam-se a precipitação química por íons contidos na água de irrigação, especialmente os carbonatos de cálcio e/ou de magnésio, bastante comuns em regiões áridas e semiáridas (MÉLO et al., 2008).

Os precipitados químicos podem ser produzidos quando as condições iniciais da água ( $\mathrm{pH}$, temperatura, sólidos dissolvidos totais) são modificadas e, sobretudo pela evaporação da água nos emissores após cada irrigação, o que aumenta a concentração dos sais dissolvidos que se precipitam ao superar o limite de solubilidade. As obstruções são formadas gradualmente e, portanto, são mais difíceis de detectar (LEITE, 1995; PIZARRO CABELLO, 1996; COELHO, 2007), sendo esses fatores mais freqüentes em climas áridos e semi-áridos.

O mercado dispõe de diversos tipos de gotejadores, apresentando diferentes sensibilidades ao entupimento (CARARO et al., 2006; MÉLO et al., 2008; COELHO \& TEIXEIRA, 2009). Segundo Coelho (2007), os gotejadores apresentam vulnerabilidade aos problemas citados, em função de possuírem estreitas passagens e pequenas aberturas.

Em virtude da falta de estudos consistentes quanto a obstrução e desobstrução de gotejadores, além disso, muitos desses estudos levam um grande tempo para serem realizados, devido às metodologias adotadas. Partindo da hipótese de que o uso de carbonato de cálcio, óxido de cálcio e sulfato de cálcio em alta concentração em tubos gotejadores via água de irrigação causam obstrução de tubos gotejadores, objetivou-se com este estudo avaliar a obstrução de emissores por precipitados químicos de carbonato de cálcio, óxido de cálcio e sulfato de cálcio em alta concentração.

\section{MATERIAL E MÉTODOS}

O ensaio foi realizado no Laboratório de Irrigação do Departamento de Engenharia Rural, da Escola Superior de Agricultura "Luiz de Queiroz" - ESALQ/USP, em Piracicaba-SP. Utilizou-se uma Bancada em estrutura metálica, com 11 metros de 
comprimento. Os tubos gotejadores foram inseridos em quatro níveis diferentes de um setor da Bancada multiobjetiva, sendo dispostos em dois sentidos em cada nível (orifícios voltados para cima e orifícios voltados para baixo). Foram utilizados os modelos de tubos gotejadores Uniram, DripNet, DripNet e Ram vazão média (0,6 L $\mathrm{h}^{-1}$ a 2,3 $\mathrm{L} \mathrm{h}^{-1}$ ). Os tubos gotejadores foram enumerados aleatoriamente (M1, M2, M3 e M4) para evitar especulação comercial dos dados.

Os produtos utilizados no ensaio foram os carbonatos de cálcio $\left(\mathrm{CaCO}_{3}\right)$, óxido de cálcio $(\mathrm{CaO})$ e sulfato de cálcio $\left(\mathrm{CaSO}_{4}\right)$, que apresentam as seguintes solubilidades em água, 0,66 mg L $\mathrm{L}^{-1}, 1,3 \mathrm{~g} \mathrm{~L}^{-1}$ e 2,45 $\mathrm{g} \mathrm{L}^{-1}$, portanto, para atender os objetivos do ensaio, foram utilizadas dosagens 10 vezes superior a esses valores para o preparo das soluções.

As aplicações foram feitas individualmente para cada tratamento nas linhas laterais com duração de 10 minutos. Antes de cada aplicação dos tratamentos, aplicou-se água potável em todas as linhas laterais durante cinco horas, sendo que a pressão utilizada durante as aplicações das soluções correspondeu à $150 \mathrm{kPa}$.

Adotou-se como um ciclo do ensaio, duas aplicações das soluções e uma leitura de vazão, repetindo-se o ciclo por duas vezes e, posteriormente foram feitas as determinações da vazão média $\left(q_{m}\right)$, do coeficiente de variação de vazão (CV) e da uniformidade de distribuição de água (UD) para cada tubo gotejador ensaiado.

Selecionaram-se 10 emissores em cada linha lateral correspondente a um determinado modelo de tubo gotejador ensaiado, sendo que o procedimento para leitura individual da vazão dos gotejadores consistiu da pressurização do sistema (150 $\mathrm{kPa}$ ), posicionamento dos coletores (recipientes plásticos) sob os respectivos gotejadores com uma defasagem de 5 segundos, retirada sequencial dos coletores após cinco minutos com defasagem de 5 segundos, transporte dos coletores à bancada de pesagem, pesagem e tabulação dos dados.

Para se obter maior exatidão foi utilizado o método gravimétrico para a determinação do volume coletado de cada emissor, expressando-se os valores de vazão em $\mathrm{L} \mathrm{h}^{-1}$. Foi utilizada uma balança de precisão certificada com precisão de $0,01 \mathrm{~g}$.

Depois de tabulados os dados de vazão, foram efetuados os cálculos da vazão e de coeficiente de variação da vazão e coeficiente de distribuição de água pelos métodos mais utilizados na literatura, destacados nas $\begin{array}{llll}\text { equações } & 1 & \text { a } & 3 .\end{array}$

$$
q=\frac{P}{1000 t} 60 \quad \text { 1) } \quad C V_{q}=\frac{s}{q} 100 \quad \text { 2) } \quad U D=\frac{q_{25 \%}}{\bar{q}} 100
$$

onde,

$\mathrm{P}$ - weigh of the collected water, g;

$\mathrm{t}$ - collection time, min;

$\mathrm{q}$ - flow rate of the used dripper, $\mathrm{L} \mathrm{h}^{-1}$;

$\mathrm{CV}_{q}$ - flow rate variation coefficient, \%;

$s$ - standard deviation of emitter discharge, $\mathrm{L}$

$\mathrm{h}^{-1}$;

UD - water distribution uniformity coefficient, \%; $q_{25 \%}$ - average flow of $1 / 4$ of the smaller values; $\mathrm{L} \mathrm{h}^{-1}$; $\bar{q}$ - average flow, $\mathrm{L} \mathrm{h}^{-1}$.

A Figura 1 mostra a Bancada de ensaios em que foi montado o experimento com o detalhe do dispositivo utilizado para aplicação das diferentes soluções nos tubos gotejadores. 

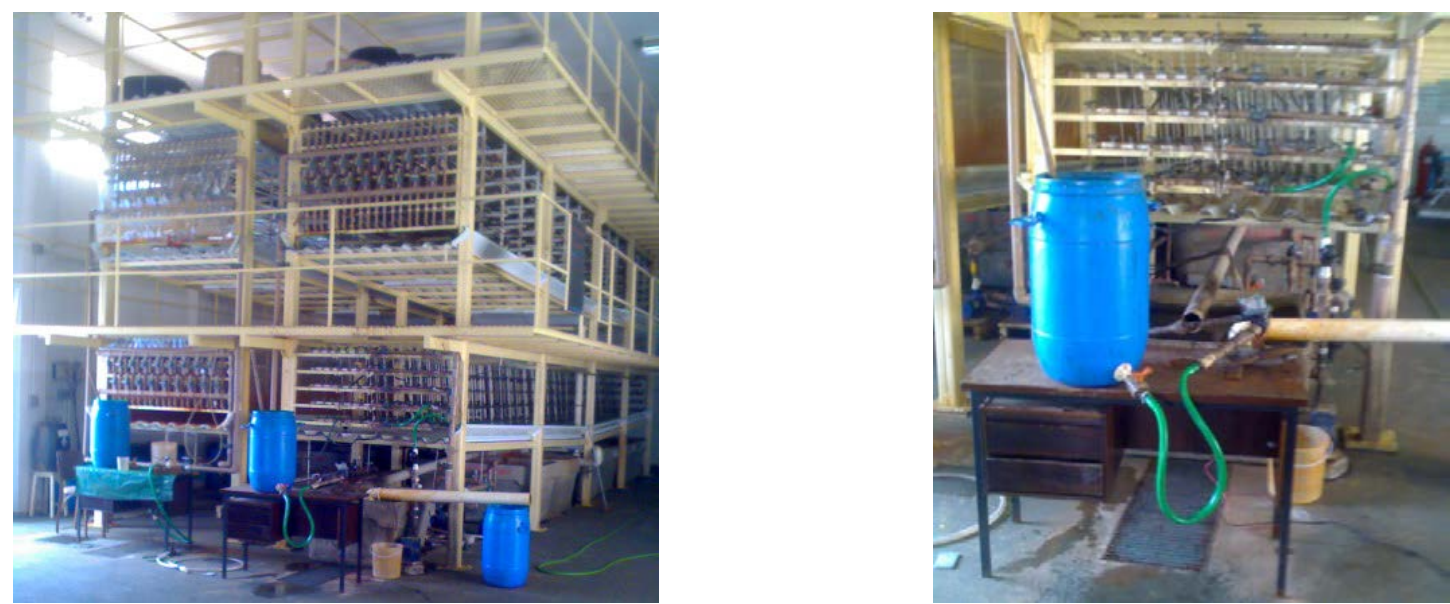

Figura 1. Vista da Bancada de ensaios e detalhe do dispositivo utilizado para aplicação das soluções em cada linha lateral.

Os dados de vazão obtidos foram submetidos à análise de variância pelo teste $\mathrm{F}$ ao nível de $0,05 \%$ de probabilidade, e em casos de significância, foi realizada a teste Tukey a $0,05 \%$ de probabilidade, utilizandose $\quad$ o programa estatístico SISVAR $^{\circledR}$ (FERREIRA, 2011).

\section{RESULTADOS E DISCUSSÃO}

Na Tabela 1 encontra-se o resumo da análise de variância para as leituras de vazão em função dos diferentes modelos de gotejadores posições dos orifícios e produto aplicado. Observa-se segundo teste $\mathrm{F}$ uma significância de $1 \%$ na $2^{\mathrm{a}}$ leitura para a interação entre modelo versus produto, já para a interação entre modelo versus posição houve interação na $1^{\mathrm{a}}$ leitura assim como na média geral das 3 leituras, para a interação produto versus posição houve interação na $3^{\mathrm{a}}$ leitura e na interação modelo versus produto versus posição houve interação para a $2^{\mathrm{a}}$ leitura de vazão.

Estes resultados mostram que houve uma interferência na combinação entre modelo e a posição de instalação assim como o produto aplicado. Trabalho realizado por Sousa et al. (2003), mostra que houve interferência do modelo e dos fertilizantes e da posição do orifício dos gotejadores na vazão. Esses mesmos autores complementam que uma boa uniformidade de distribuição de água de irrigação é fundamental para um bom manejo da fertirrigação. Entretanto, a uniformidade de distribuição de nutrientes pode ser também afetada pela variação da concentração desses na água de irrigação, a qual está relacionada com: o grau de agitação ou mistura da solução no tanque, a variação da taxa de injeção da solução e a variação da vazão no sistema de irrigação durante a fertirrigação.

Tabela 1. Resumo da análise de variância para os diferentes fatores e interação entre eles Modelo (M); Produto (Pr); Posição (P); Interação M x Pr; Interação M x P; Interação Pr x P e Interação M x Pr x P.

\begin{tabular}{lccccc}
\hline \multirow{2}{*}{ Fonte variação } & \multirow{2}{*}{ GL } & \multicolumn{3}{c}{ Quadrados Médios } \\
\cline { 3 - 6 } & 3 & $1^{\text {a }}$ Leitu & $2^{\text {a }}$ Leitu & $3^{\text {a }}$ Leitu & Média \\
\hline Modelo (M) & $24,47^{* *}$ & $22,85^{* *}$ & $24,62^{* *}$ & $23,83^{* *}$ \\
Produto (Pr) & 1 & $0,009 \mathrm{~ns}$ & $1,75^{* *}$ & $1,39^{* *}$ & $0,69^{* *}$ \\
Posição (P) & 6 & $0,0005 \mathrm{nn}$ & $0,02 \mathrm{~ns}$ & $0,01 \mathrm{~ns}$ & $0,0005 \mathrm{~ns}$ \\
Interação M x Pr & 3 & $0,03^{* *}$ & $0,65^{* *}$ & $0,36 \mathrm{~ns}$ & $0,1287 \mathrm{~ns}$ \\
Interação M x P & 2 & $0,004 \mathrm{~ns}$ & $0,01 \mathrm{~ns}$ & $0,57 \mathrm{~ns}$ & $0,19^{*}$ \\
Interação Pr x P & 2 & $0,75^{*}$ & $0,11 \mathrm{~ns}$
\end{tabular}




\begin{tabular}{|c|c|c|c|c|c|}
\hline Interação M x Pr x P & 6 & $0,002 \mathrm{~ns}$ & $0,51^{* *}$ & $0,39 \mathrm{~ns}$ & $0,12 \mathrm{~ns}$ \\
\hline Resíduo & 216 & 0,003 & 0,16 & 0,22 & 0,06 \\
\hline $\mathrm{CV}$ & & 4,06 & 27,62 & 32,99 & 17,34 \\
\hline & & \multicolumn{4}{|c|}{ Médias } \\
\hline Modelo & & \multicolumn{4}{|c|}{------------------------ L h ${ }^{-1}$---------------------- } \\
\hline RAM & & $2,15 a$ & $2,00 a$ & 1,99a & $2,05 a$ \\
\hline UNIRAM & & $1,67 b$ & $1,49 \mathrm{c}$ & $1,56 b$ & $1,57 b$ \\
\hline DRIPNET PC 1,6 & & $1,67 b$ & $1,75 b$ & $1,63 b$ & $1,68 b$ \\
\hline DRIPNET PC 0,6 & & $0,64 c$ & $0,59 d$ & $0,50 \mathrm{c}$ & $0,58 \mathrm{c}$ \\
\hline \multicolumn{6}{|l|}{ Produto } \\
\hline Carbonato & & 1,53 & $1,55 a$ & $1,54 a$ & $1,54 \mathrm{a}$ \\
\hline Óxido & & 1,533 & $1,29 b$ & $1,28 b$ & $1,36 b$ \\
\hline Sulfato & & 1,55 & $1,54 a$ & $1,45 \mathrm{ab}$ & $1,51 \mathrm{a}$ \\
\hline \multicolumn{6}{|l|}{ Posição } \\
\hline Cima & & 1,53 & 1,47 & 1,41 & 1,47 \\
\hline Baixo & & 1,53 & 1,45 & 1,43 & 1,47 \\
\hline
\end{tabular}

* Média com a mesma letra minúscula na coluna (específico por modelo de tubo gotejador) não indica diferença significativa pelo teste Tukey, a $5 \%$ de probabilidade.

As substâncias químicas dissolvidas na água de irrigação, por exemplo, o carbonato de cálcio e o sulfeto de cálcio em altas concentrações, podem precipitar e eventualmente formar incrustações nas paredes das tubulações e emissores, limitando a passagem da água. Problemas com incrustações e corrosão das tubulações podem ocorrer quando se utilizam águas subterrâneas (RIBEIRO et al., 2005).

A Tabela 2 mostra a vazão média obtida com a aplicação dos diferentes produtos químicos para as avaliações realizadas antes da aplicação do produto químico (leitura 0), após o primeiro ciclo (leitura 1) e após o segundo ciclo (leitura 2); e teste de médias, respectivamente.

Tabela 2. Vazão média $\left(\mathrm{L} \mathrm{h}^{-1}\right)$ para as duas fases de aplicação de carbonatos de cálcio $\left(\mathrm{CaCO}_{3}\right)$, óxido de cálcio $(\mathrm{CaO})$ e sulfato de cálcio $\left(\mathrm{CaSO}_{4}\right)$.

\begin{tabular}{|c|c|c|c|c|c|c|c|}
\hline \multirow{3}{*}{ Modelo } & \multirow{3}{*}{ Leitura } & \multicolumn{6}{|c|}{ Vazão média $\left(\mathrm{L} \mathrm{h}^{-1}\right)$} \\
\hline & & \multicolumn{2}{|c|}{$\left(\mathrm{CaCO}_{3}\right)$} & \multicolumn{2}{|c|}{$(\mathrm{CaO})$} & \multicolumn{2}{|c|}{$\left(\mathrm{CaSO}_{4}\right)$} \\
\hline & & Baixo & Cima & Baixo & Cima & Baixo & Cima \\
\hline \multirow[t]{3}{*}{ M1 } & 0 & 2,16 & 2,14 & 2,17 & 2,12 & 2,22 & 2,13 \\
\hline & 1 & 2,18 & 2,17 & 1,91 & 1,39 & 2,19 & 2,22 \\
\hline & 2 & 2,24 & 2,41 & 1,80 & 1,70 & 2,31 & 1,46 \\
\hline \multirow[t]{3}{*}{ M2 } & 0 & 1,64 & 1,70 & 1,64 & 1,71 & 1,68 & 1,71 \\
\hline & 1 & 1,69 & 1,72 & 0,79 & 1,54 & 1,65 & 1,59 \\
\hline & 2 & 1,55 & 1,57 & 1,42 & 1,58 & 1,81 & 1,47 \\
\hline \multirow[t]{3}{*}{ M3 } & 0 & 1,65 & 1,66 & 1,65 & 1,71 & 1,66 & 1,70 \\
\hline & 1 & 1,70 & 1,48 & 1.63 & 1,85 & 1,78 & 1,71 \\
\hline & 2 & 1,67 & 1,60 & 1,38 & 1,74 & 1,61 & 1,73 \\
\hline \multirow[t]{3}{*}{ M4 } & 0 & 0,64 & 0,63 & 0,64 & 0,63 & 0,67 & 0,64 \\
\hline & 1 & 0,64 & 0,64 & 0,60 & 0,45 & 0,57 & 0,65 \\
\hline & 2 & 0,53 & 0,69 & 0,44 & 0,19 & 0,54 & 0,65 \\
\hline
\end{tabular}


Para o M1 não ocorreu diferenças relevantes de vazão ao longo do tempo (leituras) para as aplicações de carbonato de cálcio e sulfato de cálcio com os orifícios dos gotejadores posicionados para baixo, já quando estes se encontravam posicionados para cima e sob aplicação de carbonato de cálcio demostraram um aumento de vazão na leitura 3 de 9,5\% e uma redução na vazão de 34\% quando foi aplicado sulfato de cálcio.

A aplicação de óxido de cálcio com os gotejadores voltados para cima foi a que incorreu em maior distúrbio de vazão ao longo do tempo $\left(1,39 \mathrm{~L} \mathrm{~h}^{-1}\right)$, ou seja foi verificado no M1 uma queda no valor da vazão na leitura 1 , a qual foi seguida de um aumento de vazão de $18 \%$ na leitura 2, variando deste modo os valores de vazão entre 16 e 35\%, o que sugere a incapacidade do M1 de manter a vazão constante por um período de tempo longo, quando sob aplicação de $\mathrm{CaO}$.

Para o modelo M2 ocorreu redução drástica de vazão na leitura 1 com os gotejadores voltados para baixo utilizando-se óxido de cálcio, sendo estas da ordem de $52 \%$, ocorrendo posteriormente uma recuperação de vazão média na leitura 2, ainda assim indicando uma redução de 13,4\% em comparação com a avaliação realizada antes da aplicação do $\mathrm{CaO}$, o mesmo pode ser verificado nos gotejadores voltados para cima onde a diminuição na vazão foi de aproximadamente $10 \%$.

A aplicação de $\mathrm{CaCO}_{3}$ tanto para gotejadores voltados para cima quanto para baixo, causou 8,2\% de diminuição na vazão, já quando foi aplicado $\mathrm{CaSO}_{4}$ verificou-se aumento de vazão de 7,7\% (emissores para baixo) e redução de vazão de 14\% (emissores para cima).

A vazão média obtida para a leitura 2 com o orifício dos gotejadores posicionados para baixo utilizando-se óxido de cálcio foi o menor valor de vazão média $\left(1,38 \mathrm{~L} \mathrm{~h}^{-1}\right)$ observado para o M3, no entanto para os gotejadores posicionados para cima observouse o inverso, um acréscimo de vazão de 7,6\% (leitura 1), com uma subsequente estabilização na leitura 2, o que demonstra uma boa capacidade de recuperação de vazão do M3, pois quando esta recuperação ocorreu a sua diferença para a leitura 0 foi de no máximo 3,6\%.

Comportamento contrário, mas parecido foi verificado com a aplicação de $\mathrm{CaCO}_{3}$ na leitura 1 com os gotejadores voltados para cima, onde houve um decréscimo de vazão de 10,8\%. O M3 quando foi aplicado $\mathrm{CaSO}_{4}$ e com gotejadores para cima não demonstrou alterações relevantes na vazão $(<1,8 \%)$, enquanto que para os gotejadores voltados para baixo estas foram de até $9,5 \%$.

O M4 apresentou redução na vazão para ambas as posições dos gotejadores quando sob aplicação de $\mathrm{CaO}$, mostrando uma alta susceptibilidade deste ao entupimento quando na presença $\mathrm{CaO}$. O $\mathrm{CaSO}_{4}$ quando foi aplicado com os gotejadores votados para cima praticamente manteve a vazão constante, não ocorrendo o mesmo quando os gotejadores foram voltados para baixo, pois apresentou uma diminuição gradativa na vazão de 15 e 19\% (leitura 1 e 2). A aplicação de $\mathrm{CaCO}_{3}$ só causou distúrbios de vazão a partir da leitura 2, os quais foram de 17 e 9,5\% para os gotejadores voltados para baixo e para cima, respectivamente.

Para o modelo M4 as vazões médias ao longo do tempo e em função da posição do orifício dos gotejadores de maneira geral mostrou que os menores valores de vazão média foram obtidos para a leitura 2 com os gotejadores voltados para baixo utilizando-se carbonato de cálcio e sulfato de cálcio. Azevedo \& Saad (2012) afirmam que a uniformidade de aplicação de água em áreas irrigadas influencia diretamente o manejo, a eficiência e o custo da irrigação, assim como afeta a qualidade e produtividade da cultura.

A aplicação de $\mathrm{CaCO}_{3}$ com o gotejador voltado para baixo não apresentou diferença em relação aos demais produtos utilizados, enquanto que a aplicação de $\mathrm{CaO}$ demonstrou ser mais danosa do que a aplicação de $\mathrm{CaSO}_{4}$, nesta mesma posição, indicando uma diferença de 19,2\%; quando levado em conta os gotejadores voltados para cima a aplicação de $\mathrm{CaCO}_{3}$ provocou a menor 
redução de vazão diferindo de $\mathrm{CaO}$ e $\mathrm{CaSO}_{4}$ entorno de $17,4 \%$, os quais entre si não apresentaram diferença significativa. A posição só foi significativa ou relevante para a aplicação de $\mathrm{CaSO}_{4}$, que demonstrou ser mais prejudicial quando esta é realizada com os gotejadores voltados para cima, indicando uma diferença de 14,7\% (Tabela 3).

Tabela 3. Comparação das médias obtidas em função para os três produtos carbonatos de cálcio $\left(\mathrm{CaCO}_{3}\right)$, óxido de cálcio $(\mathrm{CaO})$ e sulfato de cálcio $\left(\mathrm{CaSO}_{4}\right)$ em relação as duas posições de aplicação (para baixo e para cima).

\begin{tabular}{|c|c|c|}
\hline Produto Posição & Baixo & Cima \\
\hline & \multicolumn{2}{|c|}{$3^{\mathrm{a}}$ Leitura } \\
\hline Carbonato & 1,47abA & $1,61 \mathrm{aA}$ \\
\hline Óxido & $1,26 \mathrm{bA}$ & $1,30 \mathrm{bA}$ \\
\hline Sulfato & $1,56 \mathrm{aA}$ & $1,33 \mathrm{bB}$ \\
\hline
\end{tabular}

* Média com a mesma letra (minúscula entre produtos; maiúsculas entre posições); (comparação entre produtos químicos em cada posição do orifício do tubo gotejador) não indica diferença significativa pelo teste Tukey, a 5\% de probabilidade.

Os M2 e 3 não apresentaram diferença significativa em ambas as posições, consequentemente mantiveram suas vazões, sem variações. O M1 com gotejador voltado para baixo mostrou uma vazão $2,3 \%$ superior ao gotejador voltado para cima, o oposto do que foi verificado no M2, que com o gotejador voltado para baixo mostrou uma vazão $2,9 \%$ inferior ao observado com o gotejador voltado para cima, já o M3 e 2 não apresentaram diferença significativa entre os gotejadores voltados para baixo e para cima (Tabela 4).

Tabela 4. Comparação das médias da interação do fator Modelo (M1, M2, M3 e M4) x Posição (Para baixo e para cima).

\begin{tabular}{|c|c|c|}
\hline Modelo $\quad$ Posição & Baixo & Cima \\
\hline & \multicolumn{2}{|c|}{$1^{\mathrm{a}}$ Leitura } \\
\hline M1 & $2,18 \mathrm{aA}$ & 2,13aB \\
\hline M2 & $1,65 \mathrm{bB}$ & $1,70 \mathrm{bA}$ \\
\hline M3 & $1,65 \mathrm{bA}$ & $1,68 \mathrm{bA}$ \\
\hline M4 & $0,64 \mathrm{cA}$ & $0,63 \mathrm{cA}$ \\
\hline
\end{tabular}

* Média com a mesma letra (minúscula entre modelos; maiúsculas entre posições); (comparação entre produtos químicos em cada posição do orifício do tubo gotejador) não indica diferença significativa pelo teste Tukey, a 5\% de probabilidade.

O M2 com emissores voltados para baixo mostrou-se bastante susceptível a aplicação de $\mathrm{CaO}$, pois demonstrou uma redução de vazão drástica, de aproximadamente $51,8 \%$, enquanto que a aplicação de $\mathrm{CaCO}_{3}$ e $\mathrm{CaSO}_{4}$ não provocaram alterações significativas na vazão, a mesma disposição ao entupimento, à aplicação de $\mathrm{CaO}$ foi verificado no M1, mas com gotejadores voltados para cima, demonstrando uma redução de vazão de 35,6\%; para os demais modelos nas posições para baixo e para cima em relação ao $\mathrm{CaCO}_{3}, \mathrm{CaO}$ e $\mathrm{CaSO}_{4}$ não houve diferença significativa (Tabela 5). Duarte (2010) observou que as incrustações causadas pelas precipitações químicas de materiais como o carbonato e o sulfato de cálcio, produzem-se gradualmente e, portanto, são mais difíceis de localizar. As altas temperaturas e os altos valores de $\mathrm{pH}$ favorecem a precipitação química, a qual se 
origina por excesso de carbonatos ou sulfatos de Ca. Quando o pH da água for muito alto, ocorrerá a precipitação de substâncias químicas, como carbonato de cálcio. Para minimizar esta formação de precipitados geralmente é injetado ácido na água de irrigação para abaixar seu pH (MARQUES et al.,

2006).

Tabela 5. Comparação das médias (leitura 2) do desdobramento da interação do Modelo (RAM; UNIRAM; DRIPNET PC 1,6 e DRIPNET PC 0,6) x Posição (Para baixo e para cima); Posição (Para baixo e para cima) x Produto e Produto (carbonatos de cálcio $\left(\mathrm{CaCO}_{3}\right)$, óxido de cálcio $(\mathrm{CaO})$ e sulfato de cálcio $\left(\mathrm{CaSO}_{4}\right)$ x Posição (Para baixo e para cima).

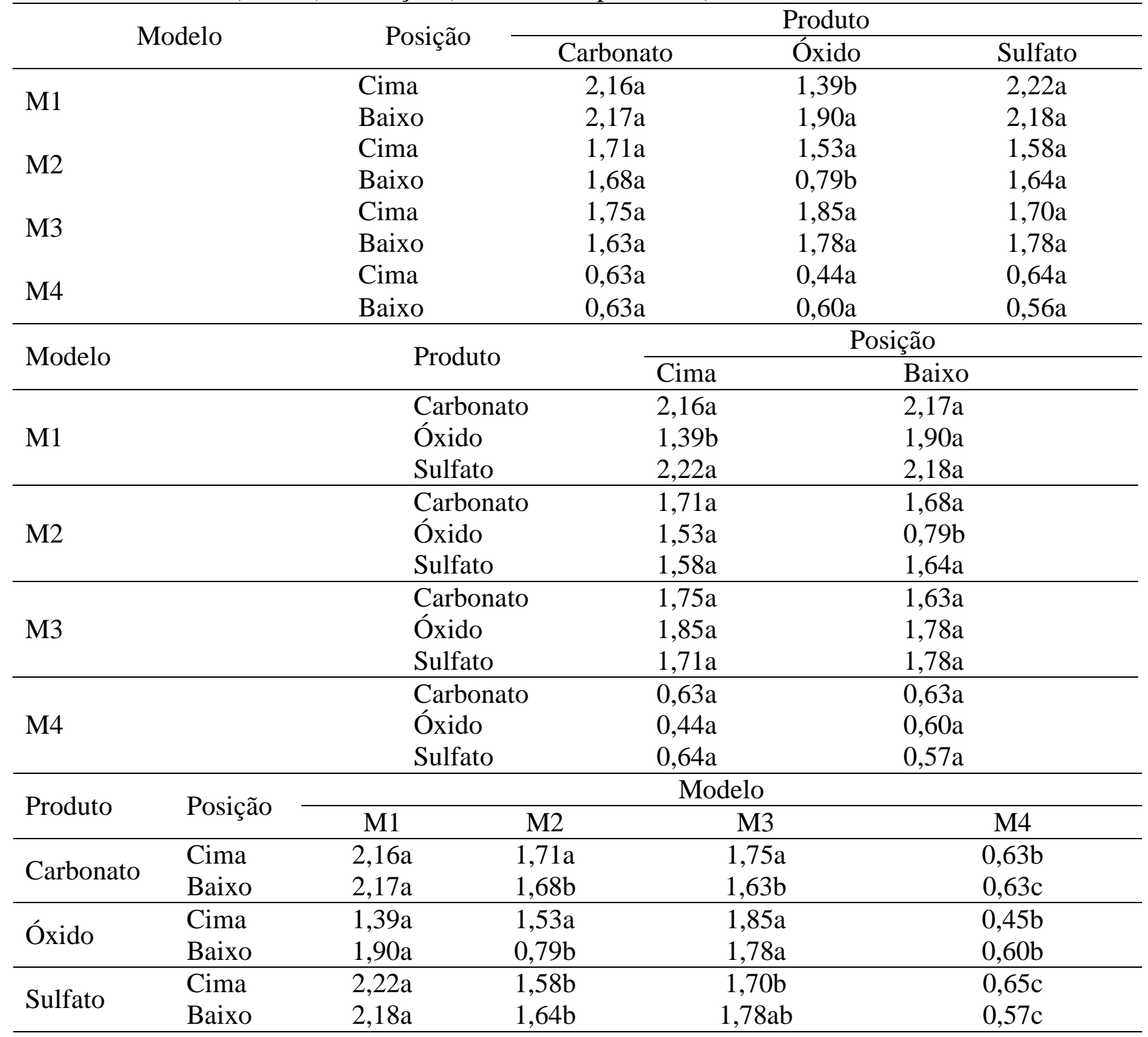

** Média com a mesma letra maiúscula na linha (Para Baixo versus Para Cima, específico por produto químico) não indica diferença significativa pelo teste Tukey, a 5\% de probabilidade.

O M1 e 2 quando aplicou $\mathrm{CaO}$ e com gotejadores voltados para cima e para baixo teve a sua vazão afetada entorno de 26,8 e $48,4 \%$, respectivamente; não havendo diferença significativa para os outros modelos com aplicação de $\mathrm{CaCO}_{3}, \mathrm{CaO}$ e $\mathrm{CaSO}_{4}$ em relação a posição.

O M2 e 3 teve a sua vazão alterada pela aplicação de $\mathrm{CaCO}_{3}$, de tal forma que esta foi aumentada em 8,6\% com gotejadores voltados para cima, enquanto que com o 


\section{USO DE CARBONATO, ÓXIDO E SULFATO DE CÁLCIO EM ALTA CONCENTRAÇÃO EM TUBOS GOTEJADORES}

gotejador voltado para baixo não se observou diferença; a utilização de $\mathrm{CaO}$ ocasionou redução de vazão no M1 de 39,6\% e de 25\% no M4 com gotejadores voltados para cima; já com gotejadores voltados para baixo houve uma diminuição na vazão menos expressiva para o $\mathrm{M} 1$ ao aplicar $\mathrm{CaO}(17,4 \%)$ e de maneira mais relevante no M2 de 50,6\%. O M1, M2, M3 e M4 demonstraram ser pouco susceptíveis ou vulneráveis a distúrbios de vazão quando sob aplicação de $\mathrm{CaSO}_{4}$, os quais foram inferiores a $10 \%$.

A Tabela 6 mostra o coeficiente de variação de vazão e uniformidade de distribuição de água obtidos com a aplicação dos diferentes produtos químicos para as avaliações realizadas antes da aplicação do produto químico (leitura 0), após o primeiro ciclo (leitura 1) e após o segundo ciclo (leitura 2), respectivamente.

Tabela 6. Coeficiente de variação de vazão (CV, \%) e uniformidade de distribuição de água (UD, \%) para as duas fases de aplicação de carbonatos de cálcio $\left(\mathrm{CaCO}_{3}\right)$, óxido de cálcio $(\mathrm{CaO})$ e sulfato de cálcio $\left(\mathrm{CaSO}_{4}\right)$.

\begin{tabular}{|c|c|c|c|c|c|c|c|c|}
\hline \multirow{2}{*}{ Mod. } & \multirow{2}{*}{ Posição } & \multirow{2}{*}{ Leitura } & \multicolumn{3}{|c|}{ CV (\%) } & \multicolumn{3}{|c|}{ (UD, \%) } \\
\hline & & & $\left(\mathrm{CaCO}_{3}\right)$ & $(\mathrm{CaO})$ & $\left(\mathrm{CaSO}_{4}\right)$ & $\left(\mathrm{CaCO}_{3}\right)$ & $(\mathrm{CaO})$ & $\left(\mathrm{CaSO}_{4}\right)$ \\
\hline \multirow[t]{6}{*}{ M1 } & Baixo & 0 & 3,60 & 2,51 & 7,30 & 96,40 & 97,49 & 92,70 \\
\hline & & 1 & 2,94 & 13,23 & 6,19 & 97,06 & 86,77 & 93,81 \\
\hline & & 2 & 5,56 & 23,75 & 14,14 & 94,44 & 76,25 & 85,86 \\
\hline & Cima & 0 & 4,96 & 4,61 & 3,64 & 95,04 & 95,39 & 96,36 \\
\hline & & 1 & 5,08 & 83,40 & 5,90 & 94,92 & 16,60 & 94,10 \\
\hline & & 2 & 7,57 & 70,67 & 93,28 & 92,43 & 29,33 & 6,72 \\
\hline \multirow[t]{6}{*}{ M2 } & Baixo & 0 & 2,62 & 1,88 & 3,56 & 97,38 & 98,12 & 96,44 \\
\hline & & 1 & 3,51 & 97,47 & 1,09 & 96,49 & 2,53 & 98,91 \\
\hline & & 2 & 18,69 & 35,50 & 25,18 & 81,31 & 64,50 & 74,82 \\
\hline & Cima & 0 & 3,74 & 3,05 & 3,05 & 96,26 & 96,95 & 96,95 \\
\hline & & 1 & 4,68 & 34,44 & 35,81 & 95,32 & 65,56 & 64,19 \\
\hline & & 2 & 13,51 & 12,33 & 34,82 & 86,49 & 87,67 & 65,18 \\
\hline \multirow[t]{6}{*}{ M3 } & Baixo & 0 & 2,78 & 2,88 & 1,82 & 97,22 & 97,12 & 98,18 \\
\hline & & 1 & 9,23 & 4,87 & 38,58 & 90,77 & 94,32 & 61,42 \\
\hline & & 2 & 9,37 & 35,45 & 12,34 & 90,63 & 64,55 & 87,66 \\
\hline & Cima & 0 & 1,85 & 2,95 & 2,36 & 98,15 & 97,05 & 97,64 \\
\hline & & 1 & 7,25 & 8,16 & 3,30 & 92,75 & 91,84 & 96,70 \\
\hline & & 2 & 35,98 & 8,18 & 6,16 & 64,02 & 91,82 & 93,84 \\
\hline \multirow[t]{6}{*}{ M4 } & Baixo & 0 & 3,47 & 5,64 & 8,53 & 96,53 & 94,36 & 91,47 \\
\hline & & 1 & 5,67 & 36,19 & 54,23 & 94,33 & 63,81 & 45,77 \\
\hline & & 2 & 52,76 & 99,76 & 52,69 & 47,24 & 0,24 & 47,31 \\
\hline & Cima & 0 & 3,56 & 3,00 & 4,95 & 96,44 & 97,00 & 95,05 \\
\hline & & 1 & 6,59 & 67,23 & 14,85 & 93,41 & 32,77 & 85,15 \\
\hline & & 2 & 15,19 & 189,14 & 10,47 & 84,81 & - & 89,53 \\
\hline
\end{tabular}

O M1 foi o tubo gotejador que apresentou o melhor comportamento frente a aplicação de dosagens elevadas de calcário

O M3 apresentou comportamento inaceitável para o segundo ciclo (leitura 2) com o orifício do gotejador voltado para cima (CV igual a 35,98\% e UD igual a 64,02\%). sendo classificado o coeficiente de variação de vazão para o mesmo como bom a médio (ASAE, 1999).

O M4 apresentou aumento de coeficiente de variação de vazão (CV) com o Orifício do gotejador voltado para baixo para a leitura 2 (52,76\%) quando comparado a 
leitura 0 (3,47\%). Apesar de não ter ocorrido redução drástica da vazão, a aplicação em elevadas dosagens de calcário ocasionou distúrbios de vazão ao longo da linha lateral.

O M4 quando posicionado para cima apresentou valor de CV após o segundo ciclo igual a $15,19 \%$, mostrando que para as condições de estudo o posicionamento do orifício afetou o funcionamento desse modelo de gotejador. No entanto, os valores de CV obtidos para o M4 após o segundo ciclo independentemente da posição do gotejador na linha lateral foram classificados como inaceitáveis (ASAE Standard EP405.1, 1999). O M2 apresentou comportamento semelhante ao M4.

Pode-se observar que após a aplicação de cal virgem (CaO), o M1 apresentou distúrbios de vazão que ocasionaram redução da vazão e da uniformidade de distribuição de água com consequente elevação do coeficiente de variação de vazão, sendo que esses distúrbios foram mais significativos com os gotejadores voltados para cima conforme as leituras 0,1 e 2 (4,61\%, 83,40\% e 70,67\%).

O M2 apresentou redução de vazão superior a $50 \%$ ao final do primeiro ciclo (leitura 1) com o gotejador voltado para baixo. No entanto, após o segundo ciclo apresentou recuperação de vazão ( $\mathrm{q}_{\mathrm{m}}$ igual a 1,42 $\mathrm{l} \mathrm{h}^{-1}$ ), mas com valor de CV inaceitável (35,50\%) e baixo valor de UD (64,50\%). Comportamento semelhante foi observado para o gotejador voltado para cima, mas com redução inferior a $10 \%$ de vazão.

O M3 apresentou redução de vazão inferior a $17 \%$ ao final do segundo ciclo de aplicação de cal virgem (leitura 2) com o gotejador voltado para baixo. Já para o gotejador voltado para cima o M3 apresentou aumento de vazão com valores de coeficiente de variação de vazão $<10 \%$ recebendo a classificação CV médio (ASAE Standard EP405.1, 1999).

A aplicação de cal virgem $(\mathrm{CaO})$ no tubo gotejador M4 ocorreram reduções de vazão que comprometeram severamente a uniformidade de distribuição de água desse emissor (valor nulo de UD para a leitura 2 com o gotejador voltado para cima). O M4 foi o mais sensível a aplicação de cal virgem com valores inaceitáveis de CV (ASAE Standard EP405.1, 1999).

Observa-se pela Tabela 6 que o M1 apresentou redução de vazão com consequente aumento de coeficiente de variação de vazão para o gotejador posicionado para baixo após o segundo ciclo de aplicação de gesso (93,28\%), mostrando que esse emissor foi sensível a aplicação de gesso em função do posicionamento do gotejador (para baixo ou para cima).

O M2 foi mais sensível a aplicação de gesso diretamente na linha lateral com os gotejadores voltados para cima, sendo observados valores de CV igual a 3,05\% (leitura 0), 35,81\% (leitura 1) e 34,82\% (leitura 2). Com os gotejadores voltados para baixo foi observado valor inaceitável para o coeficiente de variação de vazão somente após o segundo ciclo (25,18\%).

O M3 foi o que apresentou o melhor comportamento quanto á análise do CV e UD para os gotejadores posicionados para cima, pois apresentou $\mathrm{CV}<5 \%$ para as leituras 0 e 1 (CV bom) e $\mathrm{CV}<10 \%$ para a leitura 2 (CV médio) conforme a classificação proposta pela ASAE (1999).

A aplicação de gesso comprometeu o adequado funcionamento do M4 com os gotejadores posicionados para baixo, com valores de CV inaceitáveis (CV > 15\%). Para os gotejadores posicionados para cima o maior valor de CV observado foi após o primeiro ciclo de aplicação de gesso (14,85\%), ocorrendo uma manutenção da vazão após o segundo ciclo $\left(\mathrm{q}_{\mathrm{m}}=0,65 \mathrm{l} \mathrm{h}^{-1}\right)$ com redução do $\mathrm{CV}$ em relação ao primeiro ciclo (10,47\%) e aumento de UD (89,53\%).

A obstrução dos gotejadores, decorrente do tempo de funcionamento e da arquitetura diferenciada dos emissores, contribuiu para o aumento do coeficiente de variação. Mélo et al. (2008) com o objetivo de avaliar a susceptibilidade de gotejadores autocompensantes ao entupimento induzido, sob condição forçada, por precipitados químicos à base de carbonato de cálcio e 
magnésio, concluíram que a precipitação química ocorreu aleatoriamente, modificando a vazão dos gotejadores, devido à ocorrência de obstruções parciais nos mesmos.

Observou-se que os diferentes modelos de tubos gotejadores utilizados, apresentaram sensibilidade variável em função do produto químico utilizado e sentido do orifício do gotejador na linha lateral (para baixo ou para cima), com consequentes alterações de vazão média, coeficiente de variação de vazão e uniformidade de aplicação de água.

Nenhum método de avaliação da qualidade da água capaz de representar o entupimento dos emissores foi desenvolvido. A causa do entupimento varia de lugar para lugar e, para a mesma água, o entupimento depende de outras condições locais, como e características construtivas dos emissores (DUARTE, 2010).

Adequações na arquitetura, tais como: comprimento do percurso da água na parte interna do emissor, área de filtragem, localização do orifício de entrada de água no emissor em relação à seção transversal e longitudinal da mangueira, além de posicionamento do emissor na mangueira (montagem na parte superior ou inferior do tubo) etc., ou no processo de fabricação dos gotejadores avaliados podem minimizar tanto a obstrução como os efeitos ocasionados por ela (MÉLO et al., 2008).

\section{CONCLUSÕES}

O modelo M1 apresenta melhor coeficiente de variação de vazão (CV) com os gotejadores posicionados para baixo independente do tratamento químico;

O modelo M3 apresenta melhor gotejadores posicionados para cima independente do tratamento químico e $\mathrm{o}$ modelo M2 para os tratamentos químicos com calcário e cal;

O modelo M4 foi o mais sensível à aplicação de calcário após o segundo ciclo com os gotejadores posicionados para baixo e após o segundo ciclo para aplicação de cal virgem com os gotejadores voltados para cima;

O modelo M4 apresenta elevada sensibilidade após a aplicação de gesso com o gotejador posicionado para baixo;

A aplicação de cal virgem diretamente na linha lateral foi o que ocasionou os maiores distúrbios de vazão para os diferentes modelos de gotejadores ensaiados.

\section{REFERÊNCIAS BIBLIOGRÁFICAS}

ASAE Standards. Standards engineering practices data: EP405.1. Design and installation of microirrigation systems. St. Joseph, MI, Dec., 1999. p. 879-883.

AZEVEDO, L. P. \& SAAD, J. C. C. Uso de dois espaçamentos entre gotejadores na mesma linha lateral e seus efeitos sobre a formação do bulbo molhado no solo e parâmetros físicos de rabanete. Irriga, Botucatu, v. 17, n. 2, p. 148 167, abril-junho, 2012.

CARARO, D. C.; BOTREL, T. A.; HILLS, D. J.; LEVERENZ, H. L. Analysis of clogging in drip emitters during wastewater irrigation. Applied Engineering in Agriculture, St. Joseph, v.22, n. 2, p. 251257, 2006.

COELHO, R. D.; Contribuições para a irrigação pressurizada no Brasil. 2007. 192 p. Livre-Docência - Escola Superior de Agricultura “Luiz de Queiroz”, Universidade de São Paulo, Piracicaba, 2007.

COELHO, R. D.; TEIXEIRA, M. B. Chemical damages of chlorine and acids applications on compensating drippers. ASABE Annual International Meeting, Reno, Nevada, 2009. Paper Number: 95542.

DUARTE, F. V. Influência da aplicação de gás carbônico na redução de precipitação de carbonatos em sistema de irrigação localizada. 2010. 123 p. Tese (Doutorado) - Universidade Federal de Minas Gerais. Belo Horizonte, 2010. 
FERREIRA, D. F. Sisvar: a computer statistical analysis system. Ciência e Agrotecnologia (UFLA), v. 35, n.6, p. 10391042, 2011.

LEITE, J. A. O. Avaliação da susceptibilidade de tubo gotejadores ao entupimento por precipitados químicos de carbonato de cálcio. 1995. 64 p. Dissertação (Mestrado em Engenharia Agrícola) Universidade Federal de Lavras, Lavras, 1995.

MARQUES, P. A. A.; FRIZZONE, J. A.; TEIXEIRA, M. B. O estado da arte da irrigação por gotejamento subsuperficial. Colloquium Agrariae, v. 2, n.1, p. 17-31, 2006.

MÉLO, R. F. DE; COELHO, R. D.; TEIXEIRA, M. B. Entupimento de gotejadores convencionais por precipitados químicos de carbonato de cálcio e magnésio, com quatro índices de saturação de Langelier. Revista Irriga, Botucatu, v.13, n.4, p.525-539, 2008.

MÉLO, R. F. Dinâmica e controle do entupimento de gotejadores em função de precipitados químicos e fitoplâncton. 2007.
189 p. Tese (Doutorado em Agronomia) Escola Superior de Agricultura "Luiz de Queiroz”, Universidade de São Paulo, Piracicaba, 2007.

PIZARRO CABELLO, F. Riegos localizados de alta frequência. 3. ed. Madri: Mundi Prensa, 1996. 513p.

RIBEIRO, T. A.; Airoldi, R. P. S.; Paterniani, J. E. S.; Silva, M. J. M. Variação dos parâmetros físicos, químicos e biológicos da água em um sistema de irrigação localizada. Revista Brasileira de Engenharia Agrícola e Ambiental, v.9, n.3, p.295-301, 2005.

SOUSA, V. F.; FOLEGATTI, M. V.; FRIZZONE, J. A. CORREAA, R. A. L.; ALENCAR, C. M. Distribuição de fertilizantes em um sistema de fertigação por gotejamento. Revista Brasileira de Engenharia Agrícola e Ambiental, v.7, n.1, p.186-189, 2003.

TEIXEIRA, M. B.; CARARO, D. C.; COELHO, R. D. Atenção ao ferro na água de irrigação por gotejamento. FNP Consultoria \& Comércio, Agrianual 2005: anuário da agricultura brasileira, São Paulo, v.1, p.62-66, 2005. 